\title{
A PERSPECTIVA FENOMENOLÓGICO-EXISTENCIAL NA COMPREENSÃO DAS TÉCNICAS PROJETIVAS NO PSICODIAGNÓSTICO INFANTIL
}

THE PHENOMENOLOGICAL-EXISTENTIAL PERSPECTIVE IN THE COMPREHENSION OF THE PROJECTIVE TECHNIQUES FOR CHILD PSYCHODIAGNOSTIC

LA PERSPECTIVA FENOMENOLÓGICO-EXISTENCIAL EN LA COMPRENSIÓN DE LAS TÉCNICAS PROYECTIVAS EN EL PSICODIAGNÓSTICO INFANTIL

\section{Marcos Alberto Taddeo Cipullo* \\ Débora Cândido de Azevedo*}

\begin{abstract}
RESUMO
O objetivo deste artigo é discutir a possibilidade de um olhar fenomenológico-existencial aos testes projetivos, amplamente usados como instrumentos de avaliação psicológica e psicodiagnóstico. Inicialmente, o conceito de projeção é mapeado em suas diversas definições, começando pela concepção psicanalítica (que, classicamente, é entendida como "a oficial" e dá suporte às leituras e interpretaçóes dos resultados obtidos com base no traçado e nas histórias contadas pelo testando). Em seguida, serão mostradas outras perspectivas do termo, com base na visão de autores do âmbito da fenomenologia existencial, como Sartre e Merleau-Ponty. Ao longo do texto, serão feitas algumas propostas de entendimento das provas gráficas com uma metodologia fenomenológico-existencial (como exemplo, a maiêutica socrática), que não trabalha com base em critérios prévios de análise, mas entende a fundamental participação do sujeito na "doação de significados" e na devolutiva dos resultados, momento em que a análise se completa.
\end{abstract}

Palavras-chave: Técnicas projetivas. Desenho da casa-árvore-pessoa. Testes psicológicos. psicodiagnóstico. Psicologia fenomenológico-existencial.

\begin{abstract}
The purpose of this article is to discuss the possibility of an existentialphenomenological view of projective tests, widely used as instruments for psychological assessment and psychodiagnosis. Initially, the concept of projection is mapped approaching its various definitions, starting with the psychoanalytic conception (which is usually understood as the "official one",
\end{abstract}

\footnotetext{
Texto recebido em 26 de novembro de 2014 e aprovado para publicação em 5 de julho de 2016.

"Vice-presidente da Sociedade de Estudos e Pesquisa Qualitativos (SE\&PQ), professor adjunto da Universidade Federal de São Paulo, Campus Baixada Santista, membro do Departamento de Educação, Saúde e Sociedade, psicólogo e músico. E-mail: matcipullo@gmail.com.

**Mestra em Educação pela Universidade Paulista (Unip), professora no curso de Psicologia da Unip, membro da Sociedade de Estudos e Pesquisa Qualitativos (SE\&PQ), psicóloga. E-mail: deborac.azevedo@gmail.com
} 
and seconds the reading and interpretation of the results obtained based on the script and history reported by the subject). Afterwards, different perspectives of the term will be shown, grounded by the vision of authors within the existential phenomenological scope such as Sartre and MerleauPonty. Along the text, some proposed understanding of graphic tests will be made with an existential-phenomenological methodology (for instance, Socrates' maieutic method), which does not work based on previous analysis criteria, but understands the subject's fundamental role in the "donation of meanings" and in the feedback of results, when the analysis is completed.

Keywords: Projective techniques. Drawing house-tree-person. Psychological tests. Psychodiagnosis. Existential-phenomenological Psychology.

\section{RESUMEN}

El propósito de este artículo es discutir la posibilidad de una mirada existencialfenomenológica en pruebas proyectivas, ampliamente utilizadas como instrumentos de evaluación psicológica y psicodiagnóstico. Inicialmente, el concepto de proyección es observado en sus diversas definiciones, empezando con la concepción psicoanalítica (que, clásicamente, se entiende como "oficial", y da apoyo a las lecturas e interpretaciones de los resultados obtenidos con base en los dibujos y las historias contadas por los sujetos). A continuación se muestran diferentes perspectivas del término desde la visión de los autores del ámbito de la fenomenología existencial, como Sartre y Merleau-Ponty. A lo largo del texto se realizarán algunas propuestas de entendimiento de las pruebas gráficas con una metodología fenomenológicaexistencial (como por ejemplo la mayéutica socrática) que no trabaja con criterios previos de análisis, pero entiende el papel fundamental del sujeto en la "donación de significados" y en las devoluciones de los resultados, momento en el que el análisis se completa.

Palabras clave: Técnicas proyectivas. Dibujo de la casa-árbol-persona. Las pruebas psicológicas. Psicodiagnóstico. Psicología fenomenológica.

\section{INTRODUÇÃO}

Há tempos, discutimos as possibilidades para trabalharmos no âmbito da Psicologia clínica com um pressuposto existencial-humanista e utilizando um método diferenciado das Ciências Naturais, a saber, o fenomenológico. A evolução de um pensamento estrito de uma Psicologia dita científica, da tradição, fica mais explícito a partir da reformulação do psicodiagnóstico tradicional para o modelo interventivo, apresentando diferenças nos seus fundamentos epistemológicos e metodológicos, caracterizando-se como duas formas diferentes de construção da realidade. Barbieri (2010) apresenta essas diferenças paradigmáticas pela explanação dos modelos de investigação quantitativa e qualitativa nas 
pesquisas psicológicas. Busca, nos clássicos Ocampo e Cunha, a definição do psicodiagnóstico tradicional "como um processo temporalmente limitado, que emprega métodos e técnicas psicológicas para compreender os problemas, avaliar, classificar e prever o curso do caso, culminando na comunicação dos resultados” (p. 509),

Já o modelo interventivo do psicodiagnóstico se alicerça numa abordagem qualitativa de investigação científica e, em nosso caso, integra a Filosofia fenomenológica (estudo dos fenômenos como aparecem à consciência intencional). Tal modelo de psicodiagnóstico "não visa ao controle do fenômeno, mas sua compreensão, a busca do sentido da experiência vivida pelos participantes" (Barbieri, 2010, p. 507). Neste modelo há uma reformulação do "papel” do cliente e do psicólogo, que se colocam lado a lado na busca do significado da demanda trazida. "O cliente, antes agente passivo, torna-se um parceiro ativo e envolvido no trabalho de compreensão e eventual encaminhamento posterior: é corresponsável pelo trabalho desenvolvido" (Yehia, 2013, p. 33). O "foco" da investigação não está na queixa ou sintoma apontado pelos pais, mas em como esses fenômenos que causaram alguma ruptura no fluxo vivencial se inserem na existência da criança e da família, sendo necessária uma investigação de todo campo fenomenal. A "atitude" do psicólogo deixa de ser somente investigativa e passa a ser colaborativa. Como em uma pesquisa/participante, o conteúdo apresentado pelo cliente é entendido em múltiplas facetas e buscado em diversas fontes, sempre numa compreensão conjunta mediante devolutivas parciais, assim "a análise acontece simultaneamente à coleta de dados" (Barbieri, 2010, p. 507). Tais devolutivas garantem o caráter interventivo do processo e seu "objetivo", que conforme Donatelli (2013) diz:

As intervenções do psicólogo, obtidas por meio de suas percepções, se oferecem como possibilidades para ampliar o campo de consciência da pessoa, permitindo novas experimentaçôes [...] um novo sentido, que possibilite diminuir ou eliminar o sofrimento psíquico da criança e da família” (p. 48).

Tudo que foi construído em torno dessa nova modalidade de psicodiagnóstico muito contribuiu para ampliar o campo clínico, especialmente a situação de avaliação psicológica, da Psicologia fenomenológico-existencial. Agir segundo o método fenomenológico, conforme Bicudo (2011) nos apresenta, significa buscar pelo movimento de constituição do objeto que queremos conhecer, indagando a respeito da concepção de realidade que o rodeia. Não procedemos ao modo da tradição, levantando as hipóteses que o problema (queixa) nos apresenta, porque isso seria antecipar uma solução possível, mas outrossim interrogamos o fenômeno. A dúvida é uma pergunta sobre a qual não se tem respostas prévias, 
é uma perplexidade do pesquisador ante ao mundo. É preciso permanecer nessa zona de desconforto para ir buscando, esclarecendo, compreendendo, sempre em discussão com nossos pares. O rigor é garantido pela suspensão fenomenológica, ou seja, mantendo o foco no interrogado sem aprioris teóricos.

$\mathrm{Na}$ atitude fenomenológica, compreendemos que o objeto não é tomado como sendo em si ou objetivamente dado, mas é constituído pelo sujeito na intersubjetividade vivida no mundo-vida, é dado na percepção e abraçado pela consciência, compreendida como intencionalidade que significa ir em uma direção, estender-se, tender a, abrir-se, tornarse atento, dar-se conta de... É um movimento que atualiza e carrega consigo os atos, articulando seus sentidos em palavras, produzindo significados e possibilidades de expressão (Bicudo, 2016). ${ }^{1}$

Busca conhecer a realidade tal qual se apresenta o real, e o percebido é expresso pela linguagem, como um ato atualizado no presente, realizado por meio da descrição. Da comunicação de "sentidos e de significados entre pessoas que se valem da linguagem mundana, e, portanto, histórica, zonas de objetividade são constituídas" (Bicudo, 2016). A visão de mundo que permeia esse método é o mundo-vida de Husserl.

Pensando o psicodiagnóstico interventivo embasado em uma abordagem fenomenológico-existencial, requer perguntar-nos qual o lugar das técnicas projetivas e dos demais testes nesse modelo, ao que vários autores respondem que eles têm um lugar bastante específico, que o teste seria apenas um meio para obter acesso ao outro. Yehia (2009) diz que o psicólogo utiliza as situações que o teste propõe como metáforas de situações vividas pela criança em seu dia a dia, nos âmbitos escolar, familiar e social, trabalhando com ela com base em sua maneira de lidar com os estímulos. Assim, entendemos os testes como instrumentos para obter uma amplitude na compreensão do outro e não como instrumentos definidores do diagnóstico, tal como foram entendidos inicialmente por uma Psicologia psicometrista.

No entanto a definição acima parece pouco aprofundada quando pensamos em sistematizar o psicodiagnóstico interventivo de base fenomenológico-existencial com mais rigor. Principalmente quando nos referimos às técnicas projetivas, quase todas criadas com base em um referencial da teoria psicanalítica, com suas padronizações e análises fundamentadas nesse modelo. Temos então uma questão a ser posta: como interpretar a produção do sujeito nos testes psicológicos com base em um referencial existencialista e, ou, como os solicitar usando um método fenomenológico? 
Poderíamos pensar também se cabe o uso de tais técnicas quando atuamos dentro desse referencial. É possível trabalhar apenas com entrevistas livres e, no caso do psicodiagnóstico infantil, trabalhar apenas com observações ou sessões lúdicas livres. No entanto o cerne das técnicas projetivas, desenhos e histórias faz parte do universo infantil, assim como o brinquedo, de tal forma que nos vemos diante não apenas de um instrumento, mas de um idioma, de uma linguagem própria da dimensão lúdica e simbólica da infância, assim como o discurso oral é a linguagem mais direta no mundo adulto. Também

Nas imagens, é possível expressar aqueles excessos de sentido que a palavra não pode dizer quando uma urgência emotiva a torna muda [...] a palavra torna aceitável qualquer imagem, por mais terrível que esta seja, porque nela está contido um elemento de distância do vivido, um "como se", um terceiro elemento e o seu poder simbólico (Puviani, 2011, p. 18).

Com a força das imagens, desenhos e histórias fazem parte das sessões lúdicas, talvez na mesma medida em que os brinquedos; se são desenhos e histórias livres ou solicitados pelo psicólogo; se são provocados por estímulos externos ou espontâneos, esses são aspectos que merecem um estudo mais detalhado, se nos propomos a uma análise existencial e se usamos um método fenomenológico para entender a criança.

Também se faz necessário pensarmos no conceito que sempre embasou as formas de aplicação e análise de materiais gráficos (desenhos) e imaginativos (histórias) na Psicologia tradicional: a projeção. Assim como é necessário repensar o conceito de percepção à luz da abordagem fenomenológico-existencial.

Para tanto, propomos que este artigo, com seus estudos exploratórios, seja o início de uma elaboração que nos ajude a repensar o lugar das técnicas projetivas no psicodiagnóstico interventivo de base fenomenológico-existencial, inspirando novas pesquisas.

\section{SOBRE OS CONCEITOS DE PROJEÇÃO E PERCEPÇÃO}

Atualmente o uso das técnicas projetivas está ligado, quase que exclusivamente, aos fundamentos psicanalíticos, exclusividade essa possível de ser repensada. A respeito do teste de apercepção temática (TAT) e seu criador, Henry Murray, pode-se dizer que o autor toma emprestado alguns conceitos freudianos, no entanto o teor humanista de sua "teoria da personalidade ou personologia" dizia que a psicanálise de Freud "pecava por ser uma simplificação da complexidade multifacetada da motivação humana” (Silva, citado por Murray, 2005, p. 11) ao restringir-se às pulsões inconscientes, sexuais e agressivas. Nesse sentido, o criador do teste não vinculou o conceito de projeção freudiano de modo restrito 
às suas possibilidades de análise, incluindo outros elementos analíticos, como as necessidades do próprio examinando e as pressões ambientais, como projeções possíveis aos estímulos apresentados pelo teste. Desse modo, Murray já apresenta um jogo mais dinâmico entre o indivíduo e o mundo, ou seja, "A personologia procura considerar o indivíduo naquilo que ele tem de mais próprio na sua relação consigo e com o mundo" (Silva, citado por Murray, 2005, p. 12). No entanto, o uso do teste ao longo do tempo veio sedimentando-se com uma única possibilidade de análise psicanalítica. Da mesma maneira, pensamos que histórias e desenhos inspirados em estímulos definidos possam ter outra possibilidade de análise, difundida e aceita na Psicologia como técnica projetiva e com o estatuto do rigor científico. Para tanto, uma etapa necessária seria desconstruir os conceitos de projeção e de percepção.

Então nos perguntamos: se o sujeito que realiza os desenhos não está projetando ali, na folha em branco, aspectos inconscientes, o que será esse fenômeno?

De acordo com Fonseca e Mariano (2008), os testes projetivos, por se utilizarem do método psicanalítico como forma de avaliação e interpretação de seus resultados, não se adequam a uma ciência pura, já que seus achados podem variar tanto quanto o número de sujeitos. E, como partem fundamentalmente do conceito de inconsciente, acabam sempre apresentando algo específico do sujeito da aplicação, o que, de certa forma, também se opõe à natureza científica no quesito universalização.

Freud (1986) define projeção fundamentalmente como um mecanismo de defesa, a partir do qual o sujeito atribui seus próprios sentimentos e afetos a outras pessoas e situações, não os reconhecendo como seus. Mas sendo a projeção um mecanismo primitivo também, entende-se que as percepções internas e sensoriais, assim como as lembranças, influenciam a percepção do mundo atual, não caracterizando apenas os mecanismos de defesa, pois não se apresentam apenas diante dos conflitos, segundo o prefácio do manual do TAT (Tosi, citado por Murray, 2005, p. 9), sendo esse o conceito fundamental que norteia a análise desde teste. Já Hammer (1981 citado por Retondo, 2000)

Amplia o conceito de projeção de Freud, onde o que é projetado é sempre recalcado, e a define como "colocação de uma experiência interna, no mundo exterior". E completa: “... a projeção é o processo psicológico de se atribuir qualidades, sentimentos, atitudes e anseios próprios, aos objetos do ambiente (pessoas, outros organismos ou coisas). O conteúdo da projeção pode ou não ser conhecido pelo sujeito como parte de si próprio" (p. 15).

Para superarmos uma definição teórica exclusiva de uma dada abordagem e caminharmos no sentido de uma Psicologia mais ampla e comum, faz-se necessário repensar tal conceito. 
Embora Freud tenha utilizado o termo mecanismo projetivo na formulação teórica de um estudo de caso em 1913,

O uso da expressão "projetivo" enquanto algo relacionado a manifestações inconscientes em produções humanas foi utilizada pela primeira vez por L. K. Frank, em 1939. Este autor utilizou o termo projetivo para explicar a relação de "parentesco" existente entre o teste de Associação de Palavras de Jung de 1904, o teste de manchas de tintas de Rorschach de 1920, o teste do Desenho em 1923 e o TAT (Teste de Apercepção Temática) de Murray em 1935. Frank afirmou que estes testes levam a uma investigação dinâmica e holística da personalidade, sendo grandes instrumentos que o psicólogo dispõe na elaboração de um psicodiagnóstico (Fonseca \& Mariano, 2008, p. 5).

A citação demonstra o caráter projetivo dos testes citados e sua importância para a investigação dinâmica e holística da personalidade humana e sua importância para o psicodiagnóstico, no entanto desloca novamente o conceito de projeção.

A questão da projeção é fundamental para reconsiderarmos o uso de testes projetivos em outras abordagens, afastando-nos das formas tradicionais de análise. Telles (2000), falando especificamente do TAT, mostra-nos que, independentemente do posicionamento teórico seguido, é fundamental que se observe com atenção o fenômeno, ou seja, a história contada. Para que isso seja realizado a contento, é fundamental que se dê liberdade de interpretação aos resultados. Assim, novas reformulações podem surgir.

Telles (2000), no Instituto de Psicologia da Universidade de São Paulo (USP), vem trabalhando com um modelo em Psicologia que, segundo ela, aproximase mais do nosso objeto de estudo, "o homem", do que as teorias propostas por todas as escolas, buscando uma compreensão mais unitária apriorística deste. A autora busca também uma fundamentação mais objetiva, científica e epistemologicamente, sem deixar de considerar o caráter holístico do homem. Assim, em seus estudos, inova com uma metodologia que muda o enfoque teórico-interpretativo para uma análise da estrutura formal do texto do sujeito, tanto aquele obtido como material de psicoterapia como os textos advindos dos resultados de testes projetivos. Para tanto, tece um trabalho de desvinculação do TAT do conceito de "projeção" tradicional, das teorias psicanalíticas e, acoplado ao teste, pois de acordo com seu criador, "A conduta da interpretação deve ser feita a partir da identificação das necessidades e pressóes percebidas pelo sujeito, e o mais importante a descobrir num indivíduo é a direcionalidade de suas atividades, sejam elas mentais, verbais ou físicas" (Murray, 2005, p. 12).

Pensando no conceito freudiano de projeção, Telles (2000) coloca que foi inoportuno o uso desse conceito no TAT e diz que o conceito de projeção é muito mais profundo e complexo, e que não poderíamos explicá-lo somente 
pela percepção e a apercepção do indivíduo. Telles então se pergunta: como, ao longo do tempo, trocamos o conceito de apercepção (escolhido por Murray no TAT e próprio da teoria da Gestalt) pelo conceito de projeção? A autora critica os aspectos que foram ignorados nessa passagem e alerta que, debaixo da projeção, está implícita a estrutura geral do indivíduo e também sua forma sensório-perceptiva que informa sua realidade aos pares de sua espécie.

Para responder à pergunta da autora, seguindo o raciocínio da história da Psicologia, podemos pensar em sensação e percepção como as formas que compõem a noção de conhecimento empírico. De modo simples, as sensações estariam diretamente ligadas aos órgãos dos sentidos, e a percepção seria o elemento integrador do sentido que unifica todos os sentidos. No racionalismo e no empirismo, partíamos da ideia cartesiana de um objeto mundano que é percebido por um corpo, apesar dos diferentes modos de conexão pela razão ou pela experiência, esses dois tipos de Psicologia falam da percepção como uma introjeção do mundo percebido em um EU. Assim seria possível entender o conceito de projeção como contrário ao de introjeção, sendo possível estabelecer uma relação com os processos de percepção e apercepção.

Para pensarmos os conceitos de percepção e projeção, recorreremos ao filósofo francês Merleau-Ponty (1997) que, referindo-se a Cézanne e sua obra artística, diz que

A arte não é uma imitação [...] É uma operação de expressão. Assim como a palavra nomeia, isto é, apreende em sua natureza e coloca ante nós a título de objeto reconhecível o que aparecia confusamente, o pintor, [...] "objetiva", "projeta", "fixa" (p. 114, grifo do autor).

O que significa o autor da obra objetivar, "projetar" ou fixar? Poderíamos dizer que sobre o ato de desenhar é possível então pensar que no desenho se concretiza o mundo que ainda não foi dito pelo sujeito, ou então, tal mundo toma forma. O mundo significado aparece no desenho, o mundo, tal como foi percebido pela consciência intencional, ou seja, pré-reflexivo no ato de percepção, ganha um contorno singular no desenho de cada um. Assim, aquele que desenha planifica seu mundo na horizontal, põe uma figura em um fundo vazio, branco como a folha de papel, assim como o conceito de projeção da geometria que se refere à representação de uma figura em um ou até mesmo em planos variados partindo de diferentes perspectivas.

O desenho passa, então, a ser entendido com uma função diferente, como representante de um signo ou figura, expressando o campo fenomenal em um ou mais planos da existência (afetivo, corporal, social, emocional, prático, imaginativo, etc.). Um desenho, assim como uma obra de arte, uma composição 
musical, uma novela, uma tela, uma escultura, são representações de realidades mundanas do seu criador, ou melhor, realidades vividas, assim como nos diria Sartre sobre a "obra" de Flaubert, ou nos diria Merleau-Ponty sobre a obra de Cézanne.

Também Sartre (2008), ao tratar do conceito de projeção, coloca-o no âmbito do deslocamento, trazendo a ideia do nascimento do simbólico, ou seja, de que modo um elemento físico se torna símbolo do imaginário, ou como sobrecarregamos os elementos materiais com aspectos emocionais, pela atribuição de significados subjetivos. Nas entrelinhas do pensamento sartriano, é difícil falar do conceito de projeção sem tocar no conceito de percepção. Parece que ambos fazem parte do mesmo fenômeno ou, ao menos, ambos são atos da consciência intencional. Na obra A Imaginação, de 1936, Sartre trata do problema da imagem e da formação mental da imagem, via percepção, e conclui, baseado em fundamentos husserlianos, que a percepção, assim como a imaginação são atos intencionais. Segue dizendo que "os correlativos noemáticos não são menos diferentes por essência quando se trata de percepção, de imaginação, de presentificações imagísticas, de lembrança, etc.” (Sartre, 2008, p. 104), e explica "que a imagem-lembrança nada mais é aqui do que uma consciência perceptiva modificada, isto é, afetada por um coeficiente do passado" (p. 102). Nesse sentido, é possível traçar um paralelo aos estímulos dos testes que se caracterizam por imagens e, ao serem apresentados ao examinando, requerem uma imagemlembrança de todos os atos perceptivos originais, por meio de conceitos como retenção, rememoração e presentificação. Sartre (2008) busca também em Bergson algum entendimento da questão da imagem e da memória, e diz que

Toda a teoria da memória é fundada sobre a existência de um tal sujeito e sobre a possibilidade que ele tem de se apropriar de certas imagens e conservá-las. O corpo age como instrumento de seleção; graças a ele a imagem torna-se percepção [...]. Esse centro, ao mesmo tempo de reflexão e de obscuridade, que atualiza a consciência virtual, é o corpo (pp. 54-55).

Ao falar do corpo e para entender melhor o conceito de percepção, buscamos Merleau-Ponty (1990) que, em suas aulas sobre desenvolvimento infantil, pergunta: "Existem traços permanentes do desenho infantil, independentes da influência cultural?" (p. 213). Ele próprio responde, dizendo que "é impossível decidir o que retorna à cultura e o que pertence como propriedade particular à criança” (p. 213).

Tais considerações não são apenas empírico-teóricas, uma vez que MerleauPonty trabalhava no laboratório de Psicologia experimental, e suas pesquisas e experimentos, principalmente com as sensações, desembocaram em sua fenomenologia da percepção. 
Quando Merleau-Ponty (1990) nos diz que "É impossível separar a criança das influências culturais" (p. 213), devemos levar em conta que em cada desenho, em cada produção gráfica, a criança expressa seu mundo total e não apenas aspectos de seu inconsciente, ou de sua vida pessoal, revelando a integralidade homem-mundo, carregada pela herança cultural. A obra infantil expressa, então, a vida ou a vivência de mundo de dada criança, marcada temporoespacialmente por sua existência.

Outra pergunta que Merleau-Ponty (1990) levanta é: "Em que medida o desenho infantil reflete a percepção da criança?” (p. 214). O autor responde que "o desenho infantil prolonga a percepção infantil. Ele não corresponde sempre à realidade das coisas, mas à expressão de um caráter e de uma atitude” (p. 223).

Em suas aulas, Merleau-Ponty discute e critica a noção clássica da percepção que corresponde a uma teoria das sensaçôes como a percepção sendo a soma dos sentidos isolados. Nessa definição, mora um problema científico que, segundo o próprio autor, nunca foi resolvido pelos psicólogos clássicos, que seria: como se dá a reorganização das sensações dispersas que encaminhem o significado de um objeto percebido como um objeto único, inteiro? Ou como se dá a "apercepção"? O autor nos dirá que "Essas sensações não são destituídas de conexões entre elas: trata-se de um conjunto de dados provados pelo intermédio do corpo todo inteiro" (p. 192).

Chegamos aqui a uma constatação fundamental: a noção de corpo próprio como veículo de apreensão do mundo, o conceito de percepção relativo à porosidade do "ser no mundo". Quando Merleau-Ponty diz que o desenho infantil prolonga a percepção, podemos nos referir à impossibilidade de pensar mundo interno e mundo externo como entidades separadas. Assim, não é possível falar de projeção do mundo interno na folha de papel, mas como o prolongamento de minha percepção de mundo no ato de desenhar. Portanto, para falar de percepção, temos de lembrar que a consciência intencional perceptiva é do domínio do vivido, do pré-reflexivo, do imediato. A respeito dessa não separação de mundo interior e mundo exterior, (Rezende, citado por Merleau-Ponty, 1999), na apresentação das aulas da Sorbonne, diz que a fenomenologia de Merleau-Ponty também é estrutural, entendendo que, na estrutura homem-mundo, inclui-se a existência e sua significação. Significação e sentido. Sentido como significado. Sentido como uma propriedade do sentir. Sentido como rumo.

Toda a Psicologia que se diz fenomenológico-existencial está, assim como demonstrado acima, em busca do sentido, e não deve ser diferente com as técnicas projetivas. 


\section{AS TÉCNICAS PROJETIVAS A PARTIR DA ÓTICA FENOMENOLÓGICO-EXISTENCIAL}

No psicodiagnóstico fenomenológico-existencial, vários procedimentos técnicos de investigação são utilizados. Dessa maneira, os testes psicológicos são mais uma das formas possíveis para a obtenção de informações sobre o cliente. É fundamental que tais informações sejam relativizadas, contextualizadas e discutidas entre cliente e psicólogo, evitando-se generalizações que façam naufragar a singularidade desses (Dana \& Leench, 1974, citados por Cipullo, 2002).

Em um entendimento fenomenológico-existencial, devemos tomar o cuidado de não nos apoiarmos em categorias de respostas previamente existentes, pois tal atitude é contrária à própria abordagem, na qual o sujeito é sempre considerado de forma dinâmica e em situação.

Fischer (1970) afirma que, por meio dos resultados obtidos nos testes, é possível compreender a ação do sujeito em outras situaçôes existenciais análogas às encontradas na prova que realizou. Os testes podem ser entendidos como metáforas. Além disso, a autora critica as descrições clínicas que se estruturam a partir do clássico jargão "psi”, preferindo as que se referem imediatamente a fatos concretos e reais ocorridos durante o processo diagnóstico. É importante salientar que, a partir da relação psicólogo/cliente, esse processo visa, num trabalho conjunto, a compreender o vivido tal qual se apresenta no mundo-vida, e não por um viés explicativo, utilizando conceitos de um psicologismo. Evitar as palavras técnicas ou os jargões psi e utilizar descrições que se aproximam do fenômeno mesmo, como numa descrição da literatura, é um movimento do método fenomenológico que segue os ensinamentos de Husserl de "voltar às coisas mesmas", evitando as armadilhas criadas por conceitos racionais da ciência, que, ao longo do tempo, podem ser deslocados de seu significado essencial obscurecendo o ser.

Para Craddick (1975, citado por Cipullo, 2002), tanto os testes utilizados pelo psicólogo quanto seus resultados devem ser apresentados e discutidos de maneira direta e franca; isso possibilita que o cliente acrescente outras informações e, ou, visões pessoais sobre os itens avaliados.

Goto (2008), ao discutir a questão paradigmática da subjetividade humana versus a objetividade científica, aponta para uma dificuldade em entender o homem com base unicamente de leis gerais, como propõem as ciências naturais. O método fenomenológico é útil para interpretar dados do vivido sem perder o rigor científico. Seguindo os ensinamentos de Husserl, Goto afirma que "O sentido do mundo e da vida, a valorização da história, os valores da existência, 
ficam excluídas das ciências positivas" (p. 167), no caminho científico, em busca de uma objetividade universal, os métodos das Ciências Naturais ocultaram "a vida intencional subjetiva e suas atividades". E complementa que o caminho seguro para obtermos essa "profunda autocompreensão" do ser humano somente poderia vir com a fenomenologia, porque somente ela estaria disponível para alcançar o ideal de chegar à subjetividade de uma forma livre e evidente (Goto, 2008, p. 216).

Com base nessa afirmação, é possível questionar o uso dos manuais das técnicas projetivas que indicam uma única possibilidade de análise para uma resposta típica. Pois não seria possível estabelecer significados a priori e universais para a produção do sujeito. Basta que se leve em consideração o fato de o sujeito carregar sua produção de conteúdos emocionais, de mundo, de símbolos, criados a partir de seu universo imaginário e vivido. Para tanto, é necessário excluir a diferenciação (artificial) entre "mundo externo" e "mundo interno". Classicamente, o conceito de projeção das técnicas de avaliação psicológica indica que esta expressa a realidade interna do testando, como se houvesse, de fato, tal distinção; como se "mundo" não fosse um "dentro-fora" indissociável.

\section{A UTILIZAÇÃO DE DESENHOS NO PSICODIAGNÓSTICO²}

$\mathrm{Na}$ situação diagnóstica, temos um tempo para atingirmos um objetivo: conhecer ao máximo uma criança para compreendê-la em suas múltiplas facetas na tentativa de integrar o sentido da queixa em sua trama existencial, e assim poder dar algum esclarecimento e encaminhamento à situação da família.

Para conhecermos profundamente ao outro em suas dimensões do desenvolvimento, utilizamos os mais variados recursos e instrumentos que temos à mão. No caso da criança, junto ao brinquedo, às sessões de observação lúdicas, às entrevistas com os pais, às visitas domiciliar e escolar, estão os desenhos, amplamente utilizados pelos profissionais da Psicologia, e, em grande escala, escolhidos pelas próprias crianças. Além disso, os desenhos podem ser utilizados por variados grupos, incluindo pessoas com atrasos do desenvolvimento, deficientes auditivos, mudos, estrangeiros, ou em casos em que a linguagem oral não se faz presente por algum motivo. Podem também ser usados por todas as idades, adolescentes, adultos e idosos. No caso das crianças, temos a possibilidade de olhar o grafismo a partir do momento em que a criança tem condições de representatividade simbólica. Segundo as etapas de desenvolvimento propostas por Piaget, é no período pré-operatório que a criança inicia o processo de

2 Um trabalho clássico referente ao uso de desenhos na avaliação psicológica é o HTP (house, tree, person), desenvolvido por Buck (2003). Neste artigo, contudo, não iremos nos referir ao teste clássico, mas em desenhos inspirados por ele, além do desenho da família. 
associação com alguma lógica e consegue simbolizar no papel sua experiência de mundo. Por volta dos 5 anos, já é possível ver alguma conceituação; a criança tem condições de afastar-se da experiência pura e representar.

Em uma sessão de desenhos, é possível pedir um desenho livre ou solicitar algo mais estruturado. Existem crianças que gostam de desenhar, são bastante imaginativas e apresentam bons recursos motores, estas normalmente se sentem confortáveis com temas livres. Outras, no entanto, não se saem muito bem, não se julgam bons desenhistas, foram pouco estimuladas, não parecem íntimas do papel; estas preferem que lhes seja solicitado um tema. Então podemos deixar a cargo da própria criança, é possível oferecer a folha em branco e perguntar se ela gostaria de desenhar, algumas de imediato já trazem um tema de cabeça, outras ficam rodeando, titubeando, a estas podemos oferecer um tema.

Um bom tema é a casa. Quem nunca desenhou uma casa quando criança? É um tema que figura nos desenhos infantis, parecendo sempre algo familiar. Além disso, é um desenho simples, possível a várias pessoas, mesmo àquelas que se pensam más desenhistas. Também consideramos um tema apropriado, pois, afinal, esse é o símbolo do lar, da moradia, da estada no mundo. Independentemente da forma de habitação de cada criança, todos vivemos em algum lugar, espaço que compõe nossas relações privadas.

E a árvore também. Assim como outros elementos da natureza, como o Sol, a árvore é um símbolo natural conhecido por todos. É difícil pensar em uma criança que nunca viu uma árvore, por mais urbana que ela seja. A árvore também é um símbolo do desenvolvimento, nasce, cresce, precisa se alimentar, se reproduz e morre. Pode ser uma metáfora da existência, da vida natural.

O desenho da pessoa, amplamente estudado na Psicologia, traz a possibilidade do autorretrato ou da identificação de figuras próximas, como as parentais, carrega nossa autoimagem, traz o corpo para o foco de nossas reflexóes.

Podemos pensar em outros temas, como a escola e a família, que parecem mais estruturados e, portanto, mais difíceis de serem desenhados, possíveis em crianças mais velhas, em uma fase do desenvolvimento motor mais avançada.

Temassolicitados pelo psicólogo estruturam de forma diferente as possibilidades de análise, muitas vezes acabam por serem mais concretos que os desenhos livres. Para terapeutas iniciantes, os recursos mais estruturados oferecem um potencial de análise mais específico, direcionando melhor o trabalho de compreensão clínica. Sessões lúdicas livres, desenhos livres, trazem um mundo simbólico de difícil análise para iniciantes, uma linguagem ininteligível em muitos casos. 


\section{SOBRE AS CORES}

As cores podem agregar maior dimensão afetiva aos desenhos, pois nos remetem a experiências emocionais. Apesar de algumas variantes culturais, há algum consenso quando, por exemplo, dizemos que vermelho é uma cor "quente", "sensual", ou que nos lembra raiva, sangue, etc.

Merleau-Ponty (1999) cita algumas experiências de laboratório para ilustrar o fato de que "cada uma das pretensas qualidades - o vermelho, o azul, a cor, o som - está inserida em uma certa conduta" (p. 281). Por meio de pesquisas com doenças do cerebelo ou do córtex frontal, evidencia a influência das excitações sensoriais no tônus muscular, e conclui que "A cor do campo visual torna as reaçôes do sujeito mais ou menos exatas, quer se trate de executar um movimento de uma dada amplitude ou de mostrar com o dedo um comprimento determinado" (p. 282). Com isso, afirma que

O vermelho e o amarelo são favoráveis à abdução (que significa que o organismo se desvia do estímulo e retira-se para seu centro), e o azul e o verde à adução (que significa que ele se volta para o estímulo e é atraído pelo mundo). [...] as cores ou sensaçōes "se oferecem com uma fisionomia motora, estão envolvidas por uma significação vital” (p. 282).

\section{Merleau-Ponty (1999) continua suas considerações acerca das cores,} mostrando que

As reações motoras provocadas pelo azul, a conduta do azul não são efeitos no corpo objetivo... Não é no mundo do físico e pelo efeito de algum processo escondido que se constitui a fisionomia motora da cor. Seria então na consciência... Só se compreende a significação motora das cores se elas deixam de ser estados fechados sobre si mesmos ou qualidades indescritíveis oferecidas à constatação de um sujeito pensante, se elas atingem em mim uma certa montagem geral pela qual sou adaptado ao mundo (p. 283).

Para entendermos como chegamos às significações emocionais das cores, recorremos novamente a Merleau-Ponty (1999) que diz que a cor nos solicita uma forma específica de olhar, ela é

Um certo campo ou uma certa atmosfera oferecida à potência de meus olhos e de todo o meu corpo, por isso tenho "com o vermelho e o amarelo, a experiência de um arrancamento, de um movimento que se distancia do centro", e com o azul e o verde, temos a experiência do "repouso e da concentração" (p. 284).

As sensações como as cores e os sons são apenas a formatação final de uma tensão sentida primeiramente no corpo todo. A cor produz, de acordo com Merleau-Ponty (1999), 
Uma “concentração da experiência colorida”... Assim, antes de ser um espetáculo objetivo, a qualidade deixa-se reconhecer por um tipo de comportamento que a visa em sua essência, e é por isso que, a partir do momento em que meu corpo adota a atitude do azul, eu obtenho uma quase-presença do azul. Portanto não é preciso perguntar-se como e porque o vermelho significa o esforço ou a violência, o verde o repouso e a paz, é preciso reaprender a viver essas cores como nosso corpo as vive (p. 285).

De alguma forma, isso é a fenomenologia da cor: buscamos o sentido da cor, sentido como significado, sentido como propriedade do sentir. Entendemos com isso que a cor nos diz mais que o traçado e, por isso, quase sempre escolhemos oferecer lápis de cor aos desenhistas, o que não significa que os aceitarão, porém desenhos cromáticos abrem uma gama maior de possibilidades de entendimento do ser.

\section{SOBRE O INQUÉRITO}

Algumas questôes mais se colocam quando pensamos em inquéritos padronizados que apontam para a busca de respostas que possam formar um conjunto verdadeiro, que represente o dado universal. Algumas perguntas usualmente feitas nesse tipo de inquérito até são interessantes, porque abrem para uma compreensão do modo de existir. Por outro lado, outras perguntas do inquérito são, às vezes, incompreensíveis em seus objetivos mais concretos, por exemplo, o que significa (existencialmente falando) datar o desenho, se a noção de temporalidade para uma criança não está definida de modo cronológico em uma memória específica? No entanto, perguntar sobre a temporalidade, introduzir o assunto do tempo, pode levar aquele que responde a refletir sobre o passado, presente e futuro, mesmo com crianças pequenas. Em perguntas sobre o clima, por exemplo, se há vento soprando, a resposta pode nos dizer sobre as intempéries da existência ou sobre o modo como a pessoa sente a hostilidade mundana. Apesar de alguns testes terem inquéritos padronizados, percebemos que, muitas vezes, eles ficam esquecidos nas análises finais, havendo uma primazia da interpretação dos desenhos.

$\mathrm{Na}$ abordagem fenomenológico-existencial, é “imprescindível” perguntar sobre o sentido daquilo que foi desenhado. No entanto, não compartilhamos da ideia de perguntas predeterminadas, uma vez que elas buscam respostas típicas.

Buscamos a singularidade e, para tanto, podemos pensar em outro modo de nos aproximarmos mais da dinâmica existencial daquele que desenha, daquele que projeta seu mundo numa folha de papel. A Filosofia pode nos ajudar nesse sentido, quando busca respostas para questôes da vida, especialmente a Filosofia socrática, quando leva o discípulo a buscar dentro de si mesmo as respostas que 
inquietam sua existência, tal como postulado por Rudio (1998), a maiêutica socrática pode ser uma grande aliada da psicoterapia existencial. Do grego maieutiké: arte do parto, dar à luz, significa que, nessa forma de diálogo, o mestre pergunta mais do que responde, excita a reflexão ativa, ou seja, é um despertador de consciência e inteligência. Faz parte dos objetivos socráticos trazer à tona a verdade do indivíduo e estabelecer um diálogo, para que, por meio de um saber autêntico, realize-se uma mudança no outro.

Propomos, então, que os inquéritos dos desenhos solicitados em sessões diagnósticas se iluminem no modelo socrático, uma vez que seguir através do aprofundamento das perguntas em direção à própria existência do sujeito que desenhou, em vez de realizar perguntas predeterminadas, pode desvelarse um mundo existencial rico e singular. Por não haver uma padronização das respostas, não buscamos uma categorização do sujeito, nem por isso se perde de vista o rigor científico. O diálogo maiêutico como caminho para se alcançar o autoconhecimento possibilita muito mais do que um simples diagnóstico do outro. Essa forma de diálogo intersubjetivo combina muito mais com a proposta do psicodiagnóstico interventivo, que repensa o modelo tradicional e recoloca essa prática como colaborativa.

\section{CONSIDERAÇÕES FINAIS}

Não foi o propósito deste artigo esgotar o tema ou propor um novo manual de avaliação de histórias ou desenhos com temas inspirados no HTP e TAT ou em outras técnicas projetivas. $\mathrm{Na}$ verdade, o olhar fenomenológico-existencial é uma postura metodológica diante da realidade e da utilização de qualquer instrumento da Psicologia, que não pode trabalhar com base em critérios prévios de análise.

Da fenomenologia buscar-se-á a atitude fenomenológica [...] na hermenêutica, considerarse-á o fato de que toda e qualquer interpretação encontra-se sempre fundada no horizonte histórico no qual estamos inseridos [...] análise significa, então, em seu sentido original, o destecer de uma trama, e é tomada para referir-se ao ato de libertar alguém, soltar alguma coisa ou, ainda, desmontar algo (Feijoo, 2011, pp. 57-59).

Mais especificamente, ao considerarmos a Psicologia infantil na abordagem fenomenológico-existencial,

Teremos primeiramente que nos deslocar das teorias psicológicas tradicionais acerca do desenvolvimento, da personalidade, da aprendizagem da criança e, em seguida, que nos reconduzirmos ao fenômeno da experiência infantil tal como ela originariamente se mostra antes de qualquer construção de um modelo teórico-explicativo (Feijoo, 2011, p. 91). 
Nosso trabalho está fundamento na ideia acima e, todo equalquer instrumentoe procedimento usado por uma Psicologia dita fenomenológico-existencial precisa pautar-se por esses pressupostos, incluindo os testes e as técnicas projetivas. Contudo a rigorosa utilização do método fenomenológico nos permite chegar, sim, a respostas claras sobre como o cliente edifica sua existência e, nela, seu sofrimento. De acordo com essa ótica, não há distinção entre "mundo interno" e "mundo externo", desenho e "sujeito desenhante", realidade factual e realidade "gráfica". Tudo, no desenho, nas respostas, em suas projeções, fala do sujeito, pelo sujeito e para o sujeito. Mas, como dissemos anteriormente, qualquer análise somente se completa no momento da devolutiva. Somente no compartilhar da síntese alcançada pelos desenhos e respostas, exposta para o sujeito, é possível afirmar que se trata de "sua" verdade existencial. "A participação do paciente no processo, funciona como um controle da confiabilidade das intervenções" (Barbieri, 2010, p. 512).

Assim, ao falarmos de técnicas projetivas ou projeçōes, podemos finalizar com Heidegger (1988), que nos ensina sobre os nossos modos característicos de ocupação com o "mundo" (umwelt), de preocupação com os outros (mitwelt) e de ser para si mesmo (eigenwelt). Sendo o SER-COM (os outros) essencial ao dasein (ser-aí), os modos de ser se constituem sempre como poder-ser. E, na abertura do poder-ser, o dasein está implicado como projeto; assim podemos entender as "projeçôes" no desenho sempre como poder-ser, e nunca de um modo definitivo, nada define o ser, nenhuma síntese de resultados de técnicas projetivas pode ser posta na condição do "é assim", mas deve ser posta como "está assim". Nenhuma avaliação deve ser entendida como a palavra final sobre a existência do sujeito. 


\section{REFERENNCIAS}

Barbieri, V. (2010, julho-setembro). Psicodiagnóstico tradicional e interventivo: confronto de paradigmas? Psicologia: Teoria e Pesquisa, 26(3), 503-513.

Bicudo, M. A. V. (2011). Pesquisa qualitativa segundo a visão fenomenológica. São Paulo: Cortez.

Bicudo, M. A. V. (2016). A pesquisa qualitativa assumindo a postura fenomenológica. Palestra proferida na Apropuc por ocasião da reunião científica da SEPQ. São Paulo.

Buck, J. N. (2003). H. T. P.: manual e guia de interpretação. São Paulo: Vetor.

Cipullo, M. A. T. (2002). Decifrando posturas: corpo e existência na compreensão psicodiagnóstica. São Paulo: Summus.

Donatelli, M. F. (2013). Psicodiagnóstico interventivo fenomenológicoexistencial. In Ancona-Lopez, S. (Org.), Psicodiagnóstico interventivo: evolução de uma prática. (pp. 45-64). São Paulo: Cortez.

Feijoo, A. M. L. C. (2011). A existência para além do sujeito. Rio de Janeiro: IFEN; Via Verita.

Fischer, C. T. (1970). The teste as co-avaluator. Counseling Psychology, 17, 70-76.

Fonseca, A. L. B. \& Mariano, M. S. S. (2008, julho-dezembro). Desvendando o mecanismo de projeção. Psicologia \& Foco, Aracaju, 1(1), 1-8.

Freud, S. (1894). As neuropsicoses de defesa. In J. Salomão (Trad.), Edição standard brasileira das obras psicológicas completas de Sigmund Freud. (Vol. 3, pp. 53-78). Rio de Janeiro: Imago, 1986. (Publicado originalmente em 1894).

Goto, T. A. (2008). Introdução a Psicologia fenomenológica: a nova Psicologia de Edmund Husserl. São Paulo: Paulus.

Heidegger, M. (1988). Ser e tempo. (2 Vols.) Petrópolis: Vozes.

Merleau-Ponty, M. (1990). Merleau-Ponty na Sorbonne: resumo de cursos: 19491952: Filosofia e linguagem. C. M, Cesar (Trad.). Campinas: Papirus.

Merleau-Ponty, M. (1997). O olho e o espírito. (2a ed.). Lisboa: Vega. 
Merleau-Ponty, M. (1999). Fenomenologia da percepção. (2a ed.) C. A. R. Moura, Trad.). São Paulo: Martins Fontes. (Publicado originalmente em 1945).

Murray, H. A. (2005). Teste de Apercepção Temática (T. A. T.). (3a ed.) M. C. V. M. Silva (Adap. Ampl.). São Paulo: Casa do Psicólogo.

Puviani, V. (2011). O uso de desenho no trabalho clínico com crianças: teoria e técnica. S. Garavello (Trad.). Belo Horizonte: Artesã.

Retondo, M. F. N. G. (2000). Manual prático de avaliação do H. T. P. (casaárvore-pessoa) e família. São Paulo: Casa do Psicólogo.

Rudio, F. V. (1998). Diálogo maiêutico e psicoterapia existencial. São José dos Campos: Novos Horizontes.

Sartre, J. P. (2008). O ser e o nada: ensaio de Ontologia Fenomenológica. Petrópolis: Vozes.

Telles, V. S. (2000). A desvinculação do T. A. T. do conceito de "Projeção" e a ampliação de seu uso. Psicologia USP, 11(1), 63-83. Recuperado a partir de https://www.revistas.usp.br/psicousp/article/viewFile/108080/106425

Yehia, G. Y. (2009). Entre psicodiagnóstico e aconselhamento psicológico. In H. T. P. Morato, C. L. B. T. Barreto \& A. P. Nunes (Coords.), Aconselhamento psicológico numa perspectiva fenomenológica existencial. (pp. 65-71). Rio de Janeiro: Guanabara Koogan.

Yehia, G. Y. (2013). Psicodiagnóstico fenomenológico-existencial: focalizando os aspectos saudáveis. In S. Ancona-Lopez (Org.), Psicodiagnóstico interventivo: evolução de uma prática. (pp. 23-44). São Paulo: Cortez. 